Anales del Seminario de Historia de la Filosofía ISSN-e 1988-2564

http://dx.doi.org/10.5209/ASHF.61537

\title{
Sergio Rábade Romeo (1925-2018). In memoriam
}

El profesor Sergio Rábade Romeo nos dejó el pasado 27 de marzo. Nació en Saavedra (Begonte, Lugo) en 1925. Realizó sus primeros estudios en el Seminario de Mondoñedo y cursó la licenciatura de Filosofía en la Universidad Pontificia de Comillas, en Santiago de Compostela, y en la Universidad Central de Madrid donde se doctoró en 1958. En 1961 obtuvo la Cátedra de Metafísica (Ontología y Teodicea) de la Universidad de Valencia y en 1966 la de Metafísica (Crítica) en la Universidad Complutense, donde siguió desempeñando su labor docente hasta su jubilación a principios de los 90. Fue

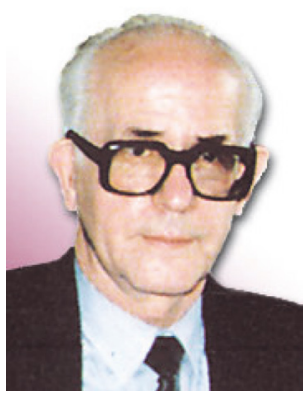
Decano de la Facultad de Filosofía de la Universidad Complutense y Vicerrector por dos veces de esta Universidad, la última en una época de importante reforma y modernización de los estudios superiores. Fue Comisario, promotor y primer Rector de la Universidad San Pablo-CEU y Director del Centro de Enseñanza Superior Don Bosco. Así como también fue director del Instituto Luis Vives de Filosofía del Consejo Superior de Investigaciones Científicas y Presidente de la Sociedad Española de Filosofía. En reconocimiento a su labor se le concedió la medalla Castelao de la Xunta de Galicia en 2001. Sus mejores discípulos y discípulas comenzaron hace ya una década la publicación de sus obras, a las que por respeto a una vida activa intelectualmente hasta la última semana de su vida, no le quisimos poner el título de "Obras completas". Ahora sí, podemos decir que tenemos esas obras al completo, ordenadas en seis volúmenes y publicadas por las editoriales Trotta y Escolar y Mayo.

En su larga y fecunda vida académica tuteló la investigación de muchos de las más relevantes profesores y profesoras que ejercen actualmente la docencia y ocupan cátedras tanto en universidades españolas como en Latinoamérica, especialmente en Argentina y Puerto Rico, país este último donde fue también profesor invitado. Sus escritos, dedicados principalmente a la Teoría del Conocimiento, ofrecen en múltiples libros y artículos una revisión histórica de los periodos y autores clásicos de la filosofía. Gracias a ellos, los hispanoparlantes hemos podido leer desde una hermenéutica inteligente y creadora a los grandes clásicos, Platón, Aristóteles, Séneca, Tomás de Aquino, Ockham, Suárez, Descartes, Locke, Spinoza, Hume, Kant, Husserl, Ortega y Gasset, Merlau-Ponty, etc., autores sobre los cuales Sergio Rábade dirigió y llevó a buen puerto más de cien tesis doctorales.

Sus investigaciones ocupan todo el espectro de la tradición filosófica analizado desde el punto de vista epistemológico. En su itinerario intelectual se pueden establecer tres etapas, que coinciden con la división clásica de la Historia de la Filosofía en ser, conciencia, lenguaje-cuerpo-sociedad. A su primera etapa pertenecen todos sus estudios histórico-sistemáticos sobre filosofía antigua y medieval, 
en la que caben resaltar obras tales como Verdad, conocimiento y ser (1965), Guillermo de Ockham y la Filosofía del s. XIV (1966), Suárez (1548-1617), Ockham (1285?-1349) y un conjunto de trabajos tan importantes como El problema de la contingencia (1959), El conocimiento del singular en la escolástica (1961), La metafísica de Séneca (1966), Teologización de la filosofía en el siglo XIV (1967), entre otros.

En la última conversación que tuve con mi maestro me preguntó, como siempre, cuál era mi nuevo objeto de investigación y después de comentarle que estaba muy interesado en los filósofos neohumeanos del siglo XX-XXI tales como B. Stroud, R. Rorty y Anne Baier, a lo cual me dio su asentimiento, me explicó, con su sentido profesoral de siempre, que si ahora empezara a trabajar, lo primero que haría sería una excelente monografía sobre Guillermo de Ockham. Yo le respondí que ya había escrito dos excelentes monografías y que gracias a ello mi generación conocía perfectamente la tradición ockhamista. De todas formas, me insistió en que si algún joven estaba interesado en encontrar los fundamentos de la filosofía moderna, no dudara en orientarlo en una investigación sobre Ockham. En la otra orilla de su primera etapa de pensamiento siempre estuvo Francisco Suárez, dirigiendo la excelente traducción, en seis volúmenes, de sus Disputaciones Metafísicas y sobre el que escribió excelentes trabajos acerca del problema del ente y sus categorías y sobre el problema de la libertad y la polémica De auxiliis.

A la segunda etapa de su pensamiento pertenecen sus obras clásicas sobre Teoría del Conocimiento y Filosofía Moderna, obras tales como Estructura del conocer humano (1966, $\left.{ }^{3} 1985\right)$, Kant. Problemas gnoseológicos de la "Crítica de la Razón Pura” (1969), Descartes y la gnoseología moderna (1971), Hume y el fenomenismo moderno (1975), Método y pensamiento en la Modernidad (1981), Espinosa: razón y felicidad (1987), entre otros. En estos trabajos Sergio Rábade realiza una perfecta reconstrucción de la Teoría del Conocimiento desde la Filosofía de la Conciencia en su doble vertiente fenomenológica y trascendental, dando lugar a un desarrollo importantísimo de temas tales como el dualismo sujeto-objeto, los elementos a priori del conocimiento, la subjetividad trascendental, la relaciones entre racionalidad y verdad, los límites del conocimiento y el problema de lo irracional, entre otros. En la autorreflexión que podemos hacer sobre esta etapa del pensamiento del Prof. Rábade, me gustaría poner de manifiesto dos líneas de argumentación.

En primer lugar, la defensa epistemológica del dualismo sujeto-objeto. En este sentido es interesante señalar que, si bien Sergio Rábade considera a Espinosa como un filósofo central en su propia autobiografía intelectual, nunca pudo estar de acuerdo con la solución monista en el problema del conocimiento, propia de la tradición Espinosa-Schelling-Hegel. En segundo lugar, la defensa de un idealismo templado por el realismo, compatible con un fenomenismo sin cosa en sí (más Hume que Kant). El mundo fenoménico es el mundo tal y como nos aparece en la organización a priori de la conciencia, al margen de lo en sí, un mundo sin substancias ni esencias. En último término, nuestra convicción de la realidad del mundo externo descansa en una evidencia inmediata, en una experiencia de la voluntad.

A su tercera etapa de pensamiento pertenecen las siguientes obras: Experiencia, cuerpo y conocimiento (1985), La razón y lo irracional (1994), Teoría del Conocimiento (1998) y Conocimiento y vida ordinaria (1999), entre otras. En ellas, Sergio Rábade culmina su peculiar tránsito de la filosofía de la conciencia a la filosofía del lenguaje-cuerpo-sociedad. Así, en Experiencia, cuerpo y conocimiento lleva a cabo 
una reconstrucción del concepto de experiencia y del papel del cuerpo en los procesos cognoscitivos, poniendo especial énfasis en las mediaciones corporales de toda experiencia. El análisis epistemológico arroja como resultado que toda experiencia debe cumplir las tres propiedades siguientes: recepción, inmediatez y concreción. Por ello, se define la experiencia cognoscitiva como aquel tipo de conocimiento que podemos adquirir con la mayor inmediatez posible, de algo concreto dado. Igualmente, la obra trata de una redención gnoseológica del cuerpo en la Filosofía Moderna, interpretando el sujeto del conocimiento no como un yo puro desmundanizado, sino como un ser mundano, experiencial y socializado. En perfecta correlación con esta obra, aparece su último trabajo titulado Conocimiento y vida ordinaria. Ensayos sobre la vida cotidiana. La realidad se constituye socialmente. Realidad y conocimiento se dan por establecidas para el hombre de la calle, pero el filósofo está obligado a reflexionar sobre la fisonomía del conocimiento ordinario. Con brillantez, nuestro filósofo asume ese papel y, desde su propio andamiaje conceptual, expone cuatro temas que siempre le habían interesado y que en este libro desarrolla pormenorizadamente, a saber: relaciones entre cultura y vida ordinaria, relaciones entre experiencia y percepción, relaciones entre cuerpo y lenguaje y relaciones entre verdad, perspectivas y creencias.

De la sociología del conocimiento recibe la idea de que el sujeto cognoscente está ya inserto en un mundo social que le precede y selecciona la receptividad del sujeto en su vida ordinaria. No hay datos primeros ni principios últimos, el conocimiento es discursivo en todos los niveles. La verdad es pública y surge de esa mediación. En este sentido, la nueva concepción del ser humano como cuerpo, lenguaje y sociedad, nos abre el camino hacia un sujeto epistemológico que es concebido como razón, voluntad y sentimientos. El Empirismo aporta a la concepción de nuestro filósofo esa dimensión pragmática de la vida cotidiana que el filósofo no puede dejar de atender. Es verdadero aquello que es útil, valioso, fomentador de la vida. Así Hume, después de dejar asentado el principio empirista del significado y haber jugado con cierto escepticismo respecto a los objetos del mundo externo y respecto a nuestro propio yo, afirmará que el conocimiento es una creencia firme y segura que posibilita la acción humana, afirmación respaldada por nuestro yo psicológico y moral, que nos orienta en el mundo de la vida.

El yo de las pasiones y de la moral es un yo encarnado en un cuerpo e insertado en una sociedad, esto es, en un mundo artificial en el que el ser humano adquiere costumbres y hábitos que le permiten crear redes sociales y mecanismos de intercambio fundados en convenciones. La identidad personal se produce a través de la experiencia social que cada sujeto va atesorando. Así pues, las pasiones, los hábitos y las costumbres instalan al ser humano en la acción y este yo, construido socialmente, es interpretado como intersubjetividad, cuya cualidad principal es la simpatía, esto es, ese principio de comunicación mediante el que los seres humanos pueden detectar los estados mentales del otro y, como resultado, pueden vivir una experiencia muy parecida. La simpatía se expresa en ese notable deseo de sociabilidad, la insociable sociabilidad de la que hablaba Kant, que impulsa a los seres humanos a agruparse y a superar la soledad.

Terminemos esta semblanza de D. Sergio Rábade con sus propias palabras, de raigambre humeana: "Volvemos, pues, al imperativo fundamental de la filosofía: centrarse en la vida y en la compleja red de sus eventos, la vida como conjunto de ocupaciones en que empleamos nuestro tiempo tanto en el fuero privado como en las 
relaciones sociales, en el mundo de los negocios, en el goce de los placeres, etc...y esta es la vida que tenemos que aclarar analizando las múltiples experiencias que tenemos de ella" (Conocimiento y vida ordinaria).

Antonio M. López Molina Universidad Complutense de Madrid 